\title{
Rancang Bangun Sistem Pengendalian Perangkat Listrik Berbasis Web Server Menggunakan Mini PC Raspberry Pi Studi Kasus Gedung Fakultas Teknik Universitas Sam Ratulangi
}

\author{
Mohamad Reza Nurkamiden, Meicsy E. I. Najoan, Muhamad D. Putro \\ Teknik Informatika Universitas Sam Ratulangi \\ 120216005@student.unsrat.ac.id, meicsynajoan@unsrat.ac.id, dwisnantoputro@unsrat.ac.id
}

\begin{abstract}
Abstrak - Konservasi Energi listrik adalah salah satu bentuk penghematan energi listrik secara efisien tanpa mengurangi penggunaan energi listrik yang dibutuhkan. Khususnya di Perguruan Tinggi UNSRAT konservasi energi listrik masih menjadi wacana dan belum terealisasi. Sebagai contoh di gedung fakultas teknik UNSRAT penggunaan sumber energi listrik masih belum dapat di kendalikan karena masih banyak peralatan listrik yang tetap menyala saat tidak sedang di gunakan. Untuk itu dibutuhkan sebuah sistem atau teknologi yang dapat mengendalikan penggunaan energi listrik di gedung tersebut. Berdasarkan masalah tersebut maka peneliti membuat sebuah sistem pengendalian perangkat listrik berbasis Web Server dengan menggunakan Mini PC Raspberry Pi dan sebuah peralatan kendali perangkat listrik menggunakan Relay Module. Dengan menerapkan sistem tersebut maka penggunaan energi listrik bisa lebih terkendali sehingga berefek pada efisiensi penggunaan sumber energi listrik.
\end{abstract}

Kata kunci : Sistem, Raspberry Pi, Listrik, Web Server, Konservasi Energi, Unsrat.

\section{PENDAHULUAN}

Energi Listrik merupakan salah satu bentuk sumber energi yang sangat dibutuhkan oleh manusia. begitu banyak aktivitas yang dilakukan oleh manusia membutuhkan energi listrik. Berdasarkan proyeksi kebutuhan listrik Indonesia yang dibuat oleh Muchlis dan Permana bahwa konsumsi listrik Indonesia terus meningkat setiap tahunnya. Pertumbuhan itu ditandai dengan meningkatnya jumlah penduduk setiap tahun sebesar $1 \%$ yang tidak sesuai dengan perkembangan Rasio Kelistrikan di Indonesia.

Dengan pertumbuhan penduduk yang terus meningkat dan Rasio kelistrikan yang tidak meningkat berdasarkan pertumbuhan penduduk menyebabkan pasokan listrik menjadi tidak merata dan sering terjadi pemadaman pada daerah - daerah tertentu karena kekurangan daya listrik. Penghematan merupakan salah satu cara untuk melakukan efisiensi terhadap sumber energi listrik, penghematan energi listrik dapat dilakukan dengan berbagai cara seperti tidak membiarkan lampu dan peralatan elektronik tetap menyala saat tidak sedang digunakan.
Permasalahan sekarang adalah pada bangunan yang besar dan jumlah bangunan yang banyak seperti di Universitas Sam Ratulangi membuat sulit untuk melakukan pemantauan dan pengendalian terhadap berbagai peralatan listrik, apalagi dengan kendali manual tentunya sangat boros waktu dan tenaga jika harus melakukan pemantauan dan pengendalian untuk setiap bangunan yang ada di Universitas Sam Ratulangi, oleh karena itu dibutuhkan sebuah sistem baru untuk dapat melakukan pemantauan dan pengendalian terhadap berbagai perangkat listrik yang ada di Universitas Sam Ratulangi khususnya di Gedung Fakultas Teknik Universitas Sam Ratulangi.

Raspberry Pi merupakan sebuah Komputer mini yang dibuat untuk dapat melakukan berbagai hal seperti Komputer pada umumnya. Raspberry Pi dapat di pakai untuk mengendalikan berbagai perangkat listrik, karena Komputer mini ini sudah dilengkapi dengan komponen Pin General Purpose Input Output (GPIO) yang berfungsi untuk dapat menerima Input dan mengeluarkan Output berdasarkan instruksi yang diberikan melalui Raspberry $P i$ secara langsung atau menggunakan Web Server untuk memberikan perintah kepada Raspberry $P i$.

\section{LANDASAN TEORI}

A. Energi Listrik

Energi listrik adalah energi utama yang dibutuhkan bagi peralatan listrik/energi yang tersimpan dalam arus listrik dengan satuan Ampere (A) dan tegangan listrik dengan satuan Volt (V) dengan ketentuan kebutuhan konsumsi daya listrik dengan satuan Watt (W) untuk menggerakkan motor, lampu penerangan, memanaskan, mendinginkan ataupun untuk menggerakkan kembali suatu peralatan Mekanik untuk menghasilkan bentuk Energi yang lain [7].

$$
W=V I t
$$

Dimana definisi notasi diatas adalah :

- $\quad \mathrm{W}=$ Energi Listrik, satuan Joule

- $\mathrm{V}=$ Beda Potensial, satuan Volt

- $\mathrm{I}=$ Kuat Arus, satuan Ampere

- $\mathrm{t}=\mathrm{Waktu}$, satuan Secont

B. Konsep Dasar Sistem Kontrol

Sistem Kontrol adalah suatu proses pengendalian atau pengaturan terhadap satu atau beberapa sistem, sehingga berada pada suatu range yang sama. Pada proses sistem kendali dapat dibagi menjadi dua bagian yaitu proses kontrol manual dan kontrol otomatis [3]. 
- Sistem Kontrol Manual

Sistem Kontrol Manual adalah suatu proses pengendalian satu atau beberapa objek dengan bantuan tenaga manusia, misalnya pengendalian saklar lampu, pengendalian komputer dan lain lain.

- Sistem Kontrol Otomatis

Sistem Kontrol Otomatis adalah suatu proses pengendalian terhadap objek tanpa bantuan tenaga manusia.

\section{Konsep Dasar Komputer}

Komputer adalah sebuah peralatan elektronik yang terdiri dari IC (Integrated Circuit) yang kecil yang terhubung dalam sebuah sistem dengan tujuan untuk menerima Input, mengolah dan mengeluarkan dalam bentuk Output [9].

Komputer dapat diklasifikasikan menjadi beberapa bagian yaitu :

- Berdasarkan Signal Masukan :

* Komputer Analog

* Komputer Digital

* Komputer Hybrid

- Berdasarkan Ukuran

* Super Komputer

* Main Frame

* Personal Komputer

* Notebook/Laptop

- Berdasarkan Tujuan Pembuatan

* General Purpose

* Special Purpose

- Berdasarkan Generasi

* Komputer Generasi Pertama (1944 - 1958)

* Komputer Generasi Kedua (1959 - 1963)

* Komputer Generasi Ketiga (1964 - 1970)

* Komputer Generasi Keempat (1970 - sampai sekarang)

D. Konsep Dasar Jaringan Komputer

Menurut John Gage, Chief Researcher dari Sun Microsystems, (1984) Jaringan Komputer adalah hubungan dari dua atau lebih komputer, dan perangkat lainnya (seperti Printer, Hard Drive Eksternal, Modem dan Router), yang terhubung bersama sehingga mereka dapat saling berkomunikasi / pertukaran dan berbagi data, perangkat keras dan sumber daya lainnya [10].

Jaringan Komputer dapat diklasifikasikan menjadi beberapa bagian sebagai berikut :

- Berdasarkan Jarak

* Local Area Networking (LAN)

* Metropolitan Area Networking (MAN)

* Wide Area Networking (WAN)

- Berdasarkan Fungsi

* Client Server

* Peer To Peer

- Berdasarkan Media Transmisi

* Jaringan Berkabel

* Jaringan Nirkabel

\section{E. Raspberry Pi}

Raspberry Pi adalah Single Board Computer (SBC) atau biasa dikenal dengan mini PC Raspberry $P i$ yang memiliki fungsi yang sama dengan komputer atau laptop pada umumnya. Raspberry Pi pertama kali dirilis pada februari tahun 2012 dan dikembangkan oleh Yayasan Nirlaba Raspberry Pi Foundation yang didalamnya merupakan Developer dan Ahli Komputer dari Universitas Cambridge, Inggris.

Pada perkembangannya Raspberry $P i$ sudah mengalami perubahan dari versi yang pertama sampai sekarang. Raspberry $P i$ yang pertama dirilis pada Februari 2012 adalah Raspberry Pi model B Versi 1 yang mengggunakan Memori RAM sebesar 256 MB, kemudian pada september 2012 dibuat lagi Raspberry $P i$ model B Versi 2 dengan perubahan pada RAM yaitu sebesar $512 \mathrm{MB}$ dan masih banyak lagi versi dari Raspberry $P i$ yang dibuat sampai dengan Raspberry P $i$ terakhir yang dibuat yaitu pada februari 2016 dengan nama Raspberry Pi 3 Model B dengan Spesifikasi dari Raspberry Pi 3 Model B sebagai berikut [5]. :

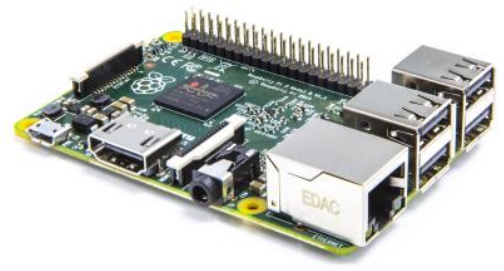

Gambar 1. Raspberry Pi 3 Model B

- $\mathrm{CPU}$ dan GPU

Raspberry pi 3 model B menggunakan Processor ARM Cortex-A53 dari Broadcom dengan Spesifikasi 64-bit Quad-Core dan berkecepatan 1,2 $\mathrm{GHz}$ dan menggunakan Broadcom Video Core IV $250 \mathrm{MHz}$ untuk GPU.

- Memory (RAM)

Pada Raspberry Pi 3 Model B ini besar RAM yang digunakan adalah 1GB LPDDR2 (900 MHz) dan jumlah itu tidak berubah dengan versi sebelumnya tapi dengan adanya Arsitektur 64-bit dari Raspberry Pi 3 model B membuat Raspberry P ini dapat bekerja lebih cepat dibandingkan dengan versi sebelumnya yang hanya menggunakan 32-bit.

- Power

Untuk sumber daya Raspberry Pi menggunakan sumber daya yang sangat sedikit yaitu dengan Tegangan 5v dan Arus minimal 1A.

- MicroSD Card

Ini adalah bagian dari Raspberry $P i$ yang berfungsi sebagai tempat untuk menyimpan OS yang digunakan oleh Raspberry $P i$ dan dapat digunakan untuk menyimpan berbagai file. Adapun standar dari microSD yang dapat digunakan pada Raspberry Pi 3 model B adalah MicroSD dengan ukuran minimal 4GB.

- Port HDMI (High Definition Multimedia Interface) Port HDMI dalam Raspberry $\mathrm{Pi}$ berfungsi sebagai media Output dari Raspberry Pi dalam bentuk gambar.

- Port Audio/Video Port A/V yang terdapat pada Raspberry Pi Model 3 ini adalah $3.5 \mathrm{~mm}$ Analog Jack Audio/Video yang berfungsi hampir sama dengan HDMI yaitu menampilkan Gambar dan Suara jika diperlukan.

- Port USB

Raspberry Pi 3 model B dilengkapi dengan 4 Port USB 2 yang memiliki fungsi sama seperti Port USB yang ada pada komputer pada umumnya. 
- $\quad$ Port LAN (RJ-45)

Port ini berfungsi untuk menghubungkan Raspberry $P i$ dengan perangkat komputer lain atau Jaringan Internet.

- Port CSI (Camera Serial Interface) Ini adalah Port yang dapat digunakan sebagai Port tambahan jika kita ingin menambahkan komponen kamera untuk Raspberry Pi dapat menggunakan Port ini.

- Port DSI (Display Serial Interface) Port ini berfungsi sebagai Port tambahan jika ingin menambahkan tambahan layar pada raspberry dengan jenis kabel Serial.

- Chip Bluetooth dan Wireless

Adalah komponen tambahan yang baru di Raspberry Pi 3 yaitu komponen Wireless dan Bluetooth yang sudah tertanam dalam Board Raspberry $P i$ sehingga lebih memudahkan bagi Raspberry $P i$ untuk dapat terhubung dengan internet dan perangkat lain tanpa menggunakan kabel.

- $\quad$ Pin GPIO (General Purpose Input Output)

GPIO adalah pin - pin pada Raspberry Pi yang berjumlah 40 pin yang dapat di Format dan digunakan sesuai kebutuhan dan merupakan pembeda antara komputer pada umumnya dengan Raspberry Pi.

\section{F. Module Relay}

Module Relay adalah sebuah rangkaian Elektromagnetik yang dioperasikan oleh perubahan kondisi suatu rangkaian listrik, pada umumnya Module Relay memiliki berbagai macam bentuk dengan kekuatan daya yang berbeda beda. Pada Relay terdapat 3 buah kaki pengendali atau pada istilah umum yang Sering digunakan yaitu Normally Open (NO) yaitu tidak terhubung saat tidak ada arus, Normally Close (NC) yaitu terhubung saat tidak ada arus dan Common sebagai pasangan dari NO dan NC yang berubah saat ada arus yang masuk ke Relay dan berikut merupakan gambaran dan cara kerja Relay [2] :

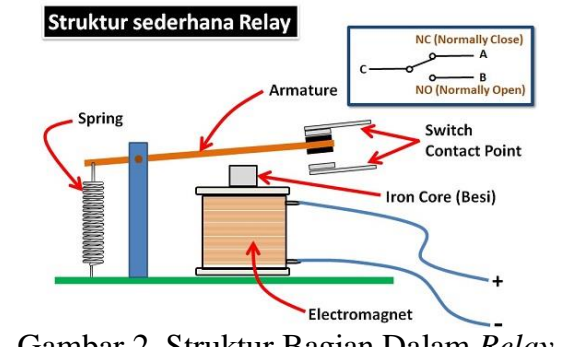

Gambar 2. Struktur Bagian Dalam Relay

Cara kerja Relay jika kumparan koil diberi arus listrik maka akan timbul medan magnet yang dapat menarik armatur pada besi yang tertanam pada kumparan koil sehingga menyebabkan berubahnya posisi Common dari NC (Normally Close) menjadi NO (Normally Open) sehingga dapat menjadi saklar yang dapat mengalirkan listrik dan jika kumparan koil kehilangan arus listrik maka armatur akan kembali ke posisi semula.

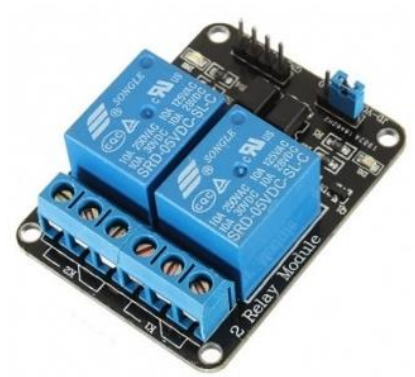

Gambar 3. Relay Module 2 Channel

\section{G. Pemrograman Web}

Pemrograman web terbagi atas dua kata yaitu Pemrogram dan Web atau website yang memiliki arti Pemrograman atau Bahasa Pemrograman adalah bahasa komputer yang digunakan dalam menulis program sedangkan website merupakan kumpulan dari halaman-halaman yang berhubungan dengan file-file lain yang saling terkait, dan berikut adalah elemen elemen penyusun halaman Website [6]:

- Hypert Text Markup Language (HTML)

Menurut Fajar Junaedi bahwa HTML adalah suatu Format data yang digunakan untuk membuat dokumen Hypertext yang dapat dieksekusi dari satu Platform komputer ke Platform komputer lainya tanpa perlu melakukan suatu perubahan apapun dengan suatu alat tertentu.

- PHP Hypertext Preprocessor (PHP)

Menurut Kasiman Peranginangin bahwa PHP adalah bahasa Script Server Side dalam pengembangan Web yang disisipkan pada dokumen HTML atau dapat di buat terpisah dari file HTML.

- Cascading Style Sheet (CSS)

Menurut Saputra CSS merupakan bahasa pemrograman web yang didesain khusus untuk mengendalikan dan membangun berbagai komponen dalam web sehingga tampilan web lebih rapih, terstruktur, dan seragam. Tujuan CSS adalah untuk memisahkan konten utama dengan dokumen lainnya (HTML dan sejenisnya).

- Javascript

Menurut Dhewiberta Hardjono JavaScript adalah bahasa pemrograman yang sederhana karena bahasa ini tidak dapat digunakan untuk membuat aplikasi ataupun applet. Dengan JavaScript kita dapat dengan mudah membuat sebuah halaman web yang interaktif.

- MySQL

Menurut Saputra MySQL bekerja menggunakan bahasa SQL (Strcture Query Langue) yang merupakan bahasa standar yang digunakan untuk manipulasi database.

H. Web Server

Web Server adalah sebuah Software dalam sebuah Server yang berfungsi menerima permintaan (Request) berupa halaman Website melalui HTTP atau HTTPs dari Client (Browser) dan mengirimkan kembali (Response) dalam bentuk halaman - halaman Website yang umumnya berbentuk HTML.

Web Server juga memilki fungsi tidak hanya mengolah data tapi dapat juga mengirimkan data berupa file foto dan video berdasarkan permintaan Client. Web Server dapat berjalan secara Online 
melalui Internet dan dapat dibuat Server Local yang dapat berjalan pada sebuah komputer dalam Jaringan Local, adapun salah satu jenis Web Server adalah Apache, Apache Server adalah Server yang memiliki banyak fungsi dan mudah dalam pengoperasian [1]..

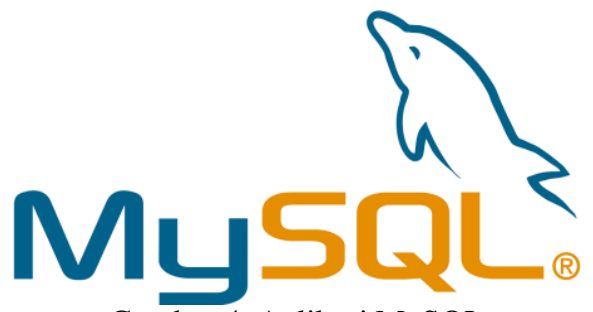

Gambar 4. Aplikasi MySQL

I. Penjadwalan Linux (Crontab)

Penjadwalan merupakan salah satu mekanisme dalam Sistem Operasi yang berkaitan dengan urutan kerja yang dilakukan sistem komputer. Pada sistem Operasi Linux penjadwalan di atur oleh sebuah Software bernama Crontab. cara kerja Software ini adalah sebagai berikut [4] :

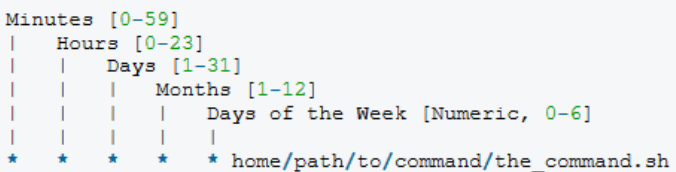

Gambar 5. Format Penjadwalan Crontab

Gambar 5 merepresentasikan format dari Aplikasi Crontab yaitu untuk simbol bintang tersebut mempunyai arti setiap saat atau setiap waktu, dan simbol bintang tersebut dapat di ganti dengan contoh format seperti berikut :

\section{8 * * 6 home/path/to/command/the_command.sh}

Gambar 6. Contoh Format Penjadwalan Crontab

Pada Gambar 6 angka 30 mewakili menit, 8 mewakili jam , dan 6 mewakili Format hari dalam seminggu sehingga jika di artikan file the_command.sh yang berada pada file home/path/to/command akan dijalankan setiap hari sabtu pukul 08.30am.

\section{J. Virtual Private Network (VPN)}

Virtual Private Network adalah sebuah bentuk komunikasi jaringan private yang memanfaatkan jaringan publik untuk bertukar infomasi. sebagai contoh misalnya dalam sebuah jalan raya dibuat sebuah jalus khusus untuk pejalan kaki dimana jalus tersebut hanya bisa dilalui oleh para pejalan kaki [8].

\section{Metodologi Penelitian}

Metodologi penelitian yang dilakukan pada pembuatan tugas akhir adalah melakukan beberapa tahap mulai dari Tinjauan Pustaka, Observasi Lapangan pada tempat yang akan di jadikan objek penelitan sampai dengan perancangan terhadap sistem yang akan di buat.

Berdasarkan Prosedur Metodologi Penelitian yang dilakukan dapat dibuat sebuah sistem Pengendalian Perangkat Listrik Berbasis Web Server menggunakan Mini
PC Raspberry Pi yang dapat di gambarkan dengan Blog Diagram seperti Gambar 7 berikut :

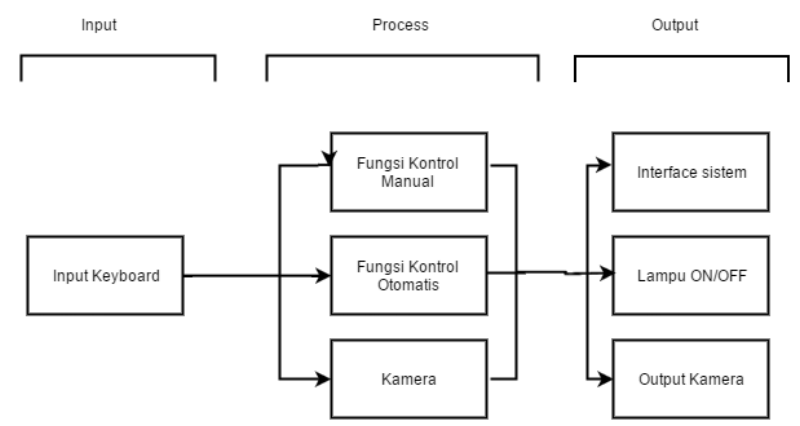

Gambar 7. Blog Diagram Sistem

Dalam melakukan pengendalian perangkat listrik tersebut sistem ini memiliki 2 fungsi utama yaitu kontrol manual menggunakan Toggle Switch dan kontrol otomatis menggunakan Crontab pada linux yang ddigambarkan seperti flowchart di bawah ini.

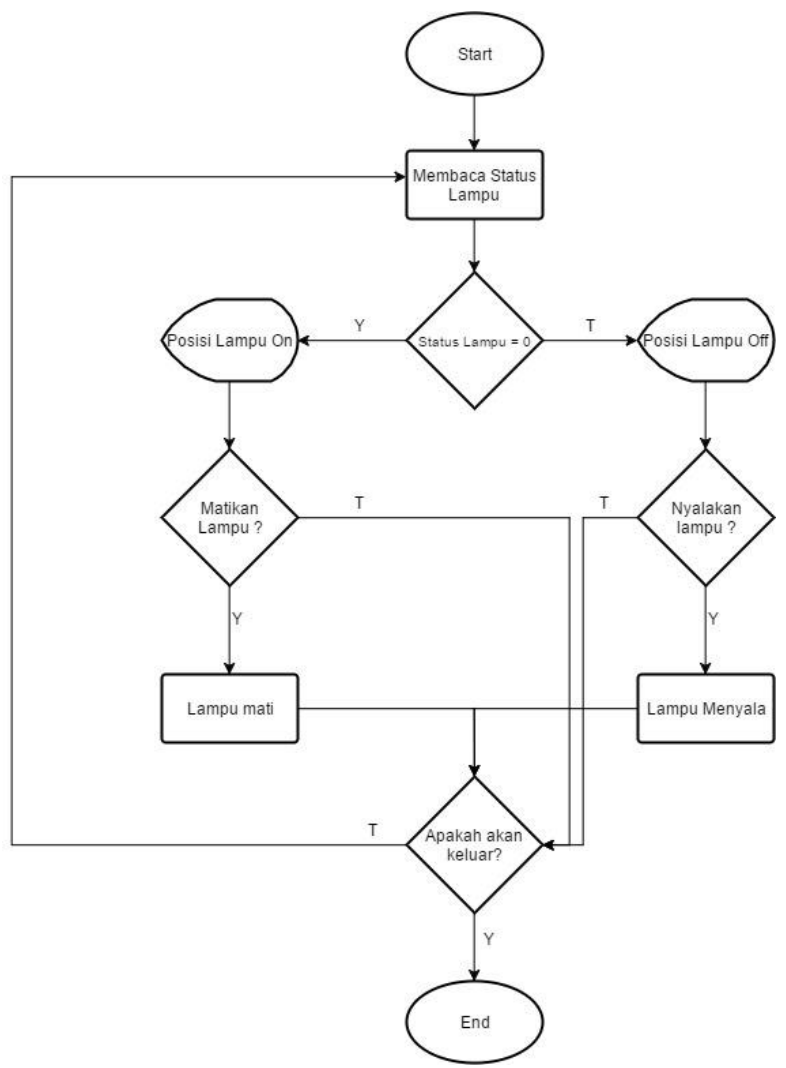

Gambar 8 Flowchart Kendali Manual 


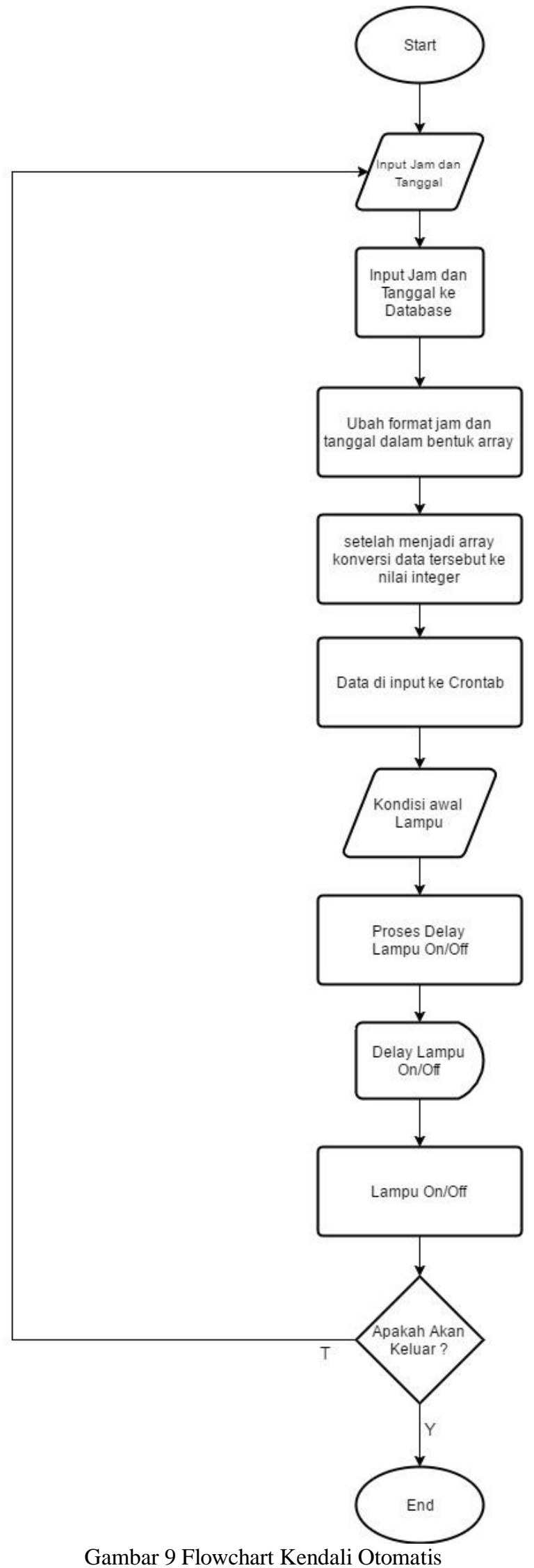

Pada pembuatan sistem ini terdapat dua bagian penting yaitu Hardware dan Software sistem. Berikut adalah perancangan Hardware dan Software dari sistem yang dibuat :
A. Perancangan Hardware

Perancangan Hardware pada penelitian ini adalah sistem dalam bentuk produk yang dapat digambarkan seperti Gambar 10 berikut :

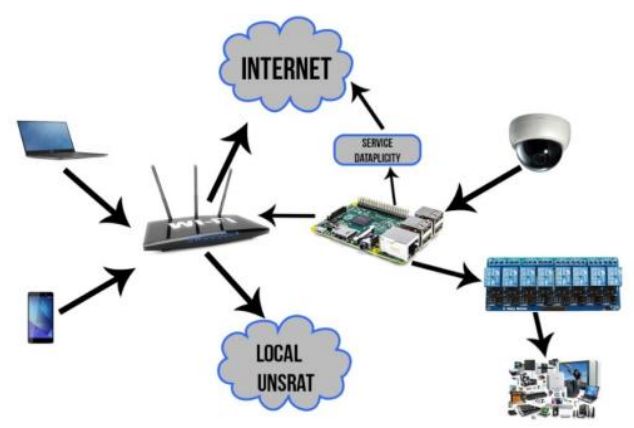

Gambar 10. Alur Sistem

- Raspberry Pi

Raspberry $P i$ dalam sistem ini digunakan sebagai Web Server sekaligus untuk kontrol perangkat listrik melalui Relay Module, untuk dapat mengontrol Relay Module tersebut pada Raspberry $P i$ terdapat Pin GPIO yang dapat di fungsikan untuk alat komunikasi dengan perangkat lain dan pada sistem ini ada 8 pin yang digunakan sebagai pin output seperti Gambar 11.

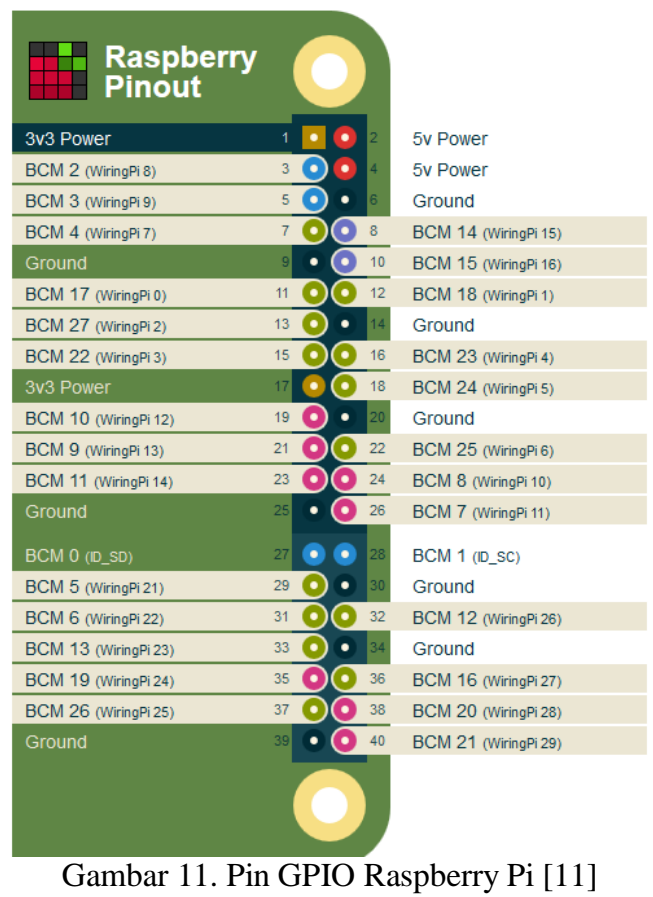

- Relay Module

Relay pada sistem ini digunakan untuk mengontrol perangkat listrik yang langsung di hubungkan melalui kabel jumper ke komputer mini Raspberry $P i$ dengan Tegangan 5V dengan spesifikasi dari Relay seperti Tabel 1.

Tabel 1. Spesifikasi Relay Module

\begin{tabular}{|c|c|c|c|c|c|c|c|}
\hline \multirow{3}{*}{$\begin{array}{l}\mathrm{A} \\
\mathrm{C}\end{array}$} & $\begin{array}{l}\text { Tega } \\
\text { ngan }\end{array}$ & Arus & Daya & \multirow{3}{*}{$\begin{array}{l}\text { D } \\
\text { C }\end{array}$} & $\begin{array}{l}\text { Tega } \\
\text { ngan }\end{array}$ & Arus & Daya \\
\hline & $125 \mathrm{~V}$ & $10 \mathrm{~A}$ & $1250 \mathrm{~W}$ & & $28 \mathrm{~V}$ & $10 \mathrm{~A}$ & $128 \mathrm{~W}$ \\
\hline & $250 \mathrm{~V}$ & $10 \mathrm{~A}$ & $2500 \mathrm{~W}$ & & $30 \mathrm{~V}$ & $10 \mathrm{~A}$ & $300 \mathrm{~W}$ \\
\hline
\end{tabular}


- Camera Serial Interface

Carema Serial Interface adalah jenis kamera yang khusus dibuat untuk dapat ditambahkan pada mini PC Raspberry Pi, Camera Tersebut dapat digunakan untuk mengambil gambar dan video. Tetap pada pembuatan sistem ini camera tersebut fungsinya dimanipulasi dari hanya untuk menganbil gambar dan video menjadi kamera realtime yang diakses melalui web browser.

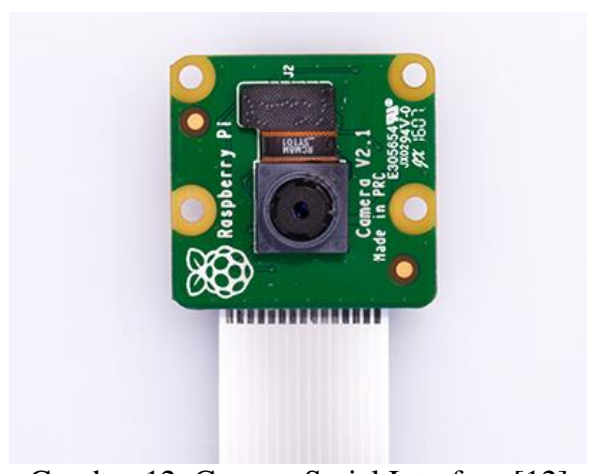

Gambar 12. Camera Serial Interface [12]

\section{B. Perancangan Software}

Perancangan Software pada pembuatan sistem ini adalah membuat sebuah aplikasi berbasis Web Server Untuk dapat memantau dan mengendalikan perangkat listrik tersebut dari mana saja melalui interface website.

Perancangan Interface Website di lakukan untuk mempermudah user dalam berinteraksi dengan sistem.Website yang dibuat adalah Website One Page yaitu Website yang hanya memiliki 1 halaman dan sudah memuat segala isi dan fungsi dari Website tersebut, Website ini juga di rancang menggunakan Framework Bootstrap sehingga tampilan dari Website ini sudah responsive yaitu dapat menyesuaikan ukuran Website berdasarkan ukuran dari setiap layar yang mengakses sistem ini dan berikut adalah rancangan dari Website yang akan di buat.

Pada interface ini terdapat halaman untuk melihat kedaaan realtime dari tempat yang dijadikan penelitian dan sebuah tombol yang terhubung langsung dengan ruangan atau tempat tersebut.

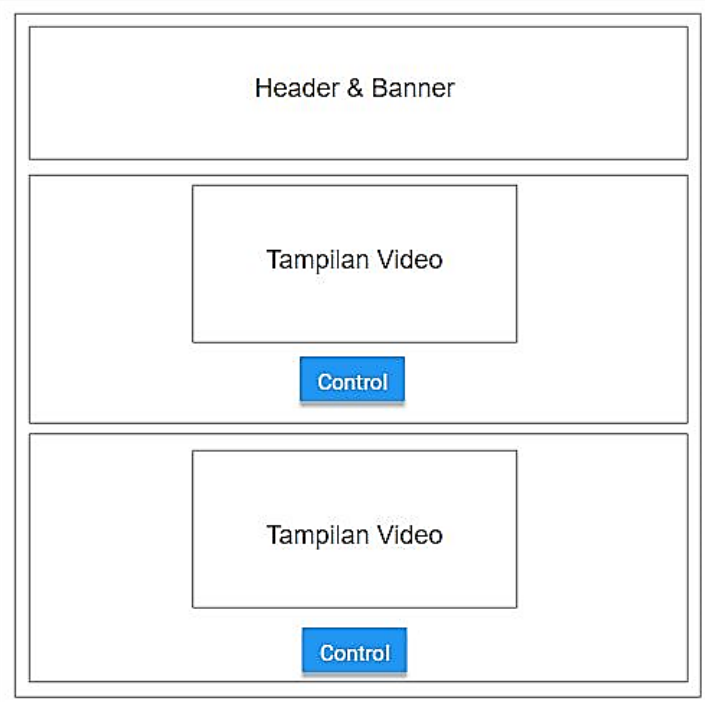

Gambar 13. Homepage Sistem
Setelah user menekan salah satu tombol kontrol seperti pada Gambar 13, kemudian user akan di arahkan ke halaman baru yang berisi semua kendali untuk ruangan tersebut, Dan berikut adalah tampilan dari halaman kontrol ruangan tersebut :

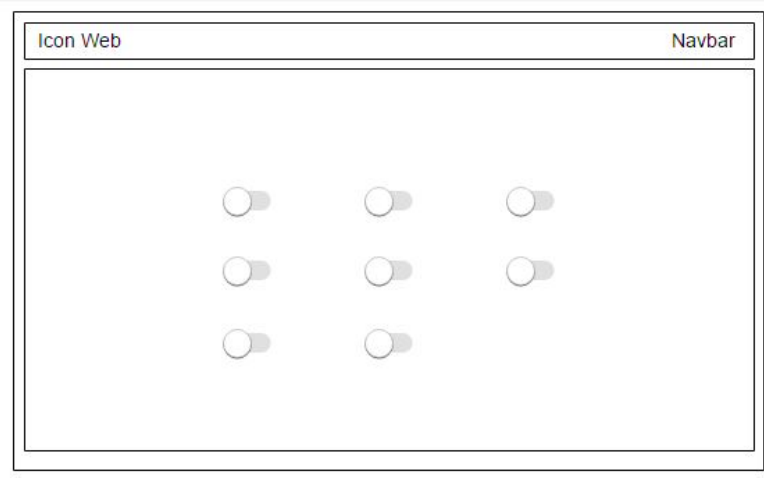

Gambar 14 Kendali Manual

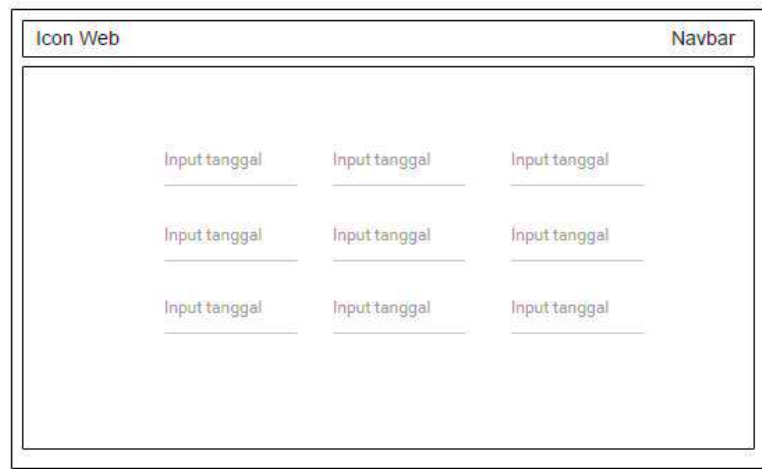

Gambar 15 Kendali Otomatis

Pada Gambar 14 dan 15 terdapat tombol kendali untuk perangkat listrik tersebut dalam bentuk tombol atau Switch yang dapat langsung di tekan atau dengan menggunakan penjadwalan untuk menyalakan atau mematikan perangkat listrik.

Setelah membuat interface website langkah terakhir adalah melakukan konfigurasi terhadap sistem agar website yang digunakan pada sistem tersebut dapat diakses melalui jaringan internet.

Untuk menghubungkan Raspberry $P i$ ke internet di gunakan sebuah layanan online bernama Dataplicity. Cara kerja layanan ini adalah apabila Raspberry $P$ terhubung ke internet maka aplikasi Client Dataplicity yang berada di Raspberry Pi akan membuat komunikasi ke layanan Dataplicity sehingga Raspberry $P i$ dapat di akses melalui jaringan internet. dan berikut adalah gambaran dari cara kerja layanan Dataplicity. 


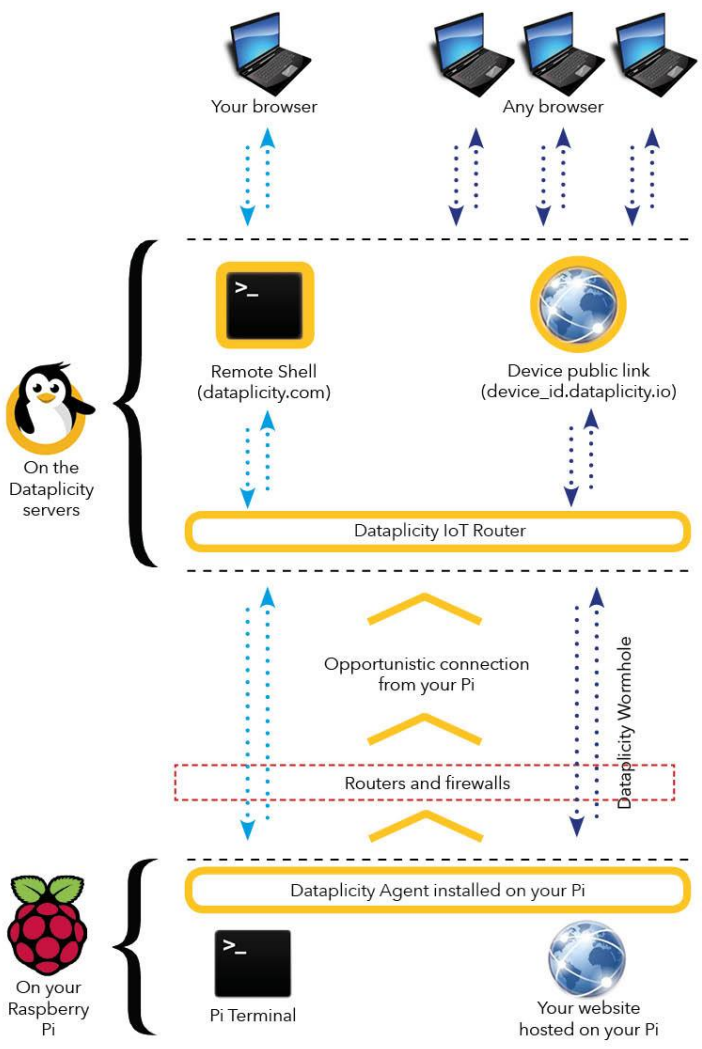

Gambar 16. Cara Kerja Dataplicty [13]

\section{IV.HASIL DAN PEMBAHASAN}

\section{A. Hasil Penelitian}

Berdasarkan prosedur penelitian yang di lakukan, didapatkan hasil penelitian berupa sebuah sistem pengendalian perangkat listrik berbasis Web Server yang dapat di akses dari jaringan Local ataupun jaringan internet. Berikut adalah hasil dari pembuatan sistem yang terbagi atas 2 bentuk yaitu Hardware dan Software.

- Hardware

Hasil dari penelitian dalam bentuk Hardware adalah sebuah sistem kontrol perangkat listrik dengan menggunakan Raspberry Pi sebagai pusat kontrol perangkat listrik yang menerima dan meneruskan perintah ke Relay Module untuk menghidupkan atau mematikan perangkat listrik.

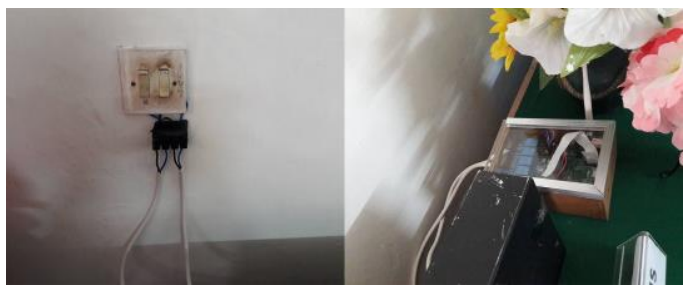

Gambar 17. Instalasi sistem di Gedung A

Gambar 17 adalah gambar rangkaian dari Raspberry $P i$ yang dipasang pada salah satu bangunan di Fakultas Teknik UNSRAT. Kabel yang terdapat pada Saklar tersebut adalah kabel yang terhubung langsung dengan Sumber listrik yang ada pada bangunan tersebut, dan diteruskan ke Relay Module agar dapat di kendalikan melalui Sistem Tersebut.

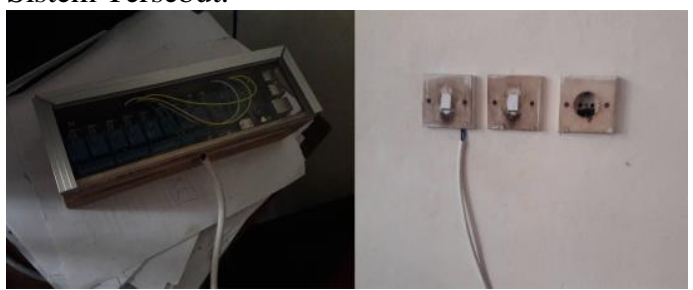

Gambar 18. Instalasi Sistem di Gedung B

Tidak berbeda dengan rangkaian pada Gambar 17, rangkaian peralatan seperti Gambar 18 dipasang pada bangunan yang berbeda tempat. Agar dapat diamati dan diuji.

- Software

Dalam pembuatan Interface sistem peneliti menggunakan Framework Bootstrap dimana pada Website ini terdapat sebuah halaman utama yang berisi tampilan realtime kamera dan sebuah tombol untuk masing - masing ruangan seperti berikut :

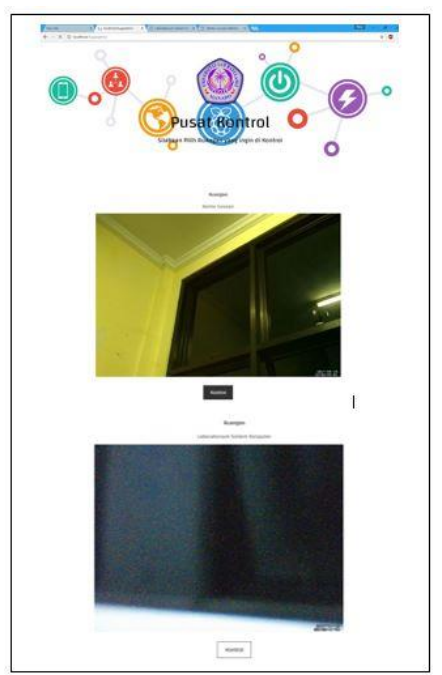

Gambar 19. Tampilan Homepage Sistem

Selain itu terdapat halaman kontrol untuk masing masing halaman yang terpasang sistem tersebut dengan tampilan kontrol seperti berikut :

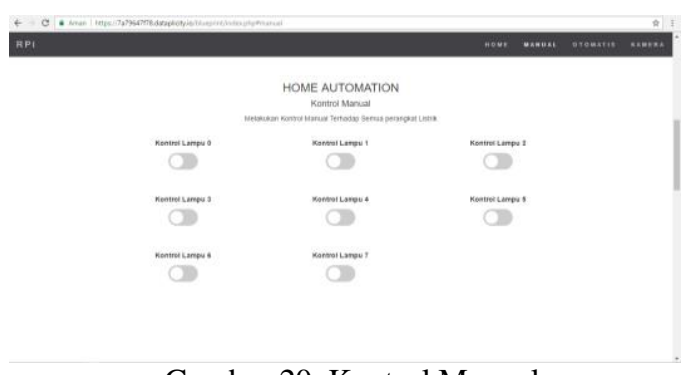

Gambar 20. Kontrol Manual

Gambar 20 adalah tampilan Software sistem dalam bentuk website dimana terdapat Tombol atau Switch untuk kendali masing - masing Peralatan listrik melalui Relay Module. 


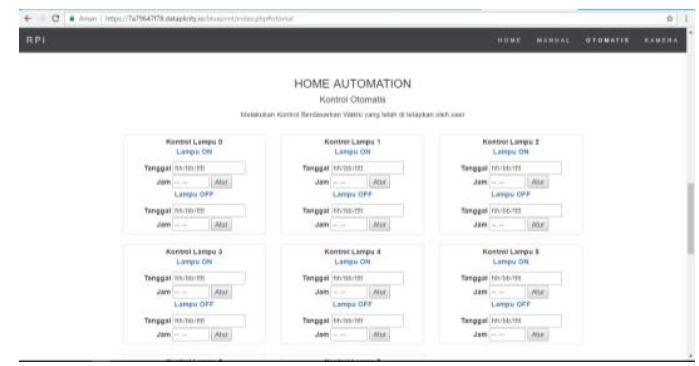

Gambar 21. Kontrol Otomatis

Selain kendali menggunakan tombol atau Switch terdapat juga kendali otomatis untuk setiap peralatan listrik yang dapat di atur sesuai keinginan penggunan sistem untuk menghidupkan atau mematikan peralatan listrik.

- Uji Coba Sistem

Uji Coba sistem bertujuan untuk mengetahu kelebihan dan kekurangan sistem yang dibuat serta kelayakan dari sistem untuk dapat digunakan dalam jangka waktu yang sangat lama.

* Pengujian Response Server

Pengujian Respon Server adalah pengujian tentang kecepatan respon dari Server untuk memproses perintah dari User dalam menyalakan sebuah lampu, dan pada percobaan ini peneliti mencoba 3 buah lampu yang di uji menggunakan jaringan internet pada waktu yang berbeda yaitu pagi, siang sore dan malam sebagai berikut.

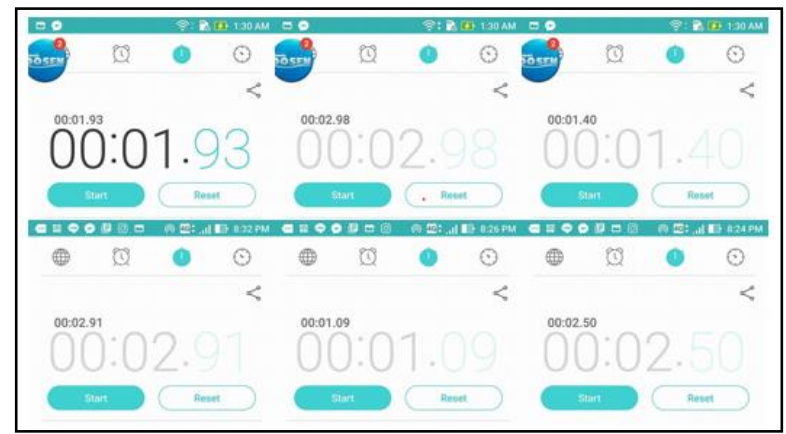

Gambar 22. Screencapture Percobaan Response Server

Data dari Gambar 22 tersebut dapat dilihat pada Tabel 1 berikut :

Tabel 1. Tabel Hasil Percobaan Response Server

\begin{tabular}{|c|c|c|c|c|}
\hline \multirow{2}{*}{$\begin{array}{c}\text { Nama } \\
\text { Alat }\end{array}$} & \multicolumn{4}{|c|}{ Waktu Pengujian } \\
\cline { 2 - 5 } & $\begin{array}{c}\text { Pagi } \\
(07.33)\end{array}$ & $\begin{array}{c}\text { Siang(0 } \\
1.30)\end{array}$ & $\begin{array}{c}\text { Sore }(3.27 \\
)\end{array}$ & $\begin{array}{c}\text { Malam(0 } \\
8.32)\end{array}$ \\
\hline Lampu & 2,77 & 1,63 & 1,45 & 2,50 \\
1 & Detik & Detik & Detik & Detik \\
\hline Lampu & 1,96 & 2,11 & 1,85 & 1,09 \\
2 & Detik & Detik & Detik & Detik \\
\hline Lampu & 2,06 & 1,35 & 2,06 & 2,91 \\
3 & Detik & Detik & Detik & Detik \\
\hline
\end{tabular}

Berdasarkan data diatas rata rata respons dari Server sampai bisa menyalakan sebuah lampu adalah 1,98 detik. Jadi dapat disimpulkan bahwa faktor utama yang mempengaruhi kinerja sistem adalah jaringan intenet, jika jaringan internet lambat maka proses yang di lakukan Server untuk mengirimkan data menjadi lambat.

* Pengujian Sistem Pada Browser yang Berbeda Pengujian ini bertujuan untuk melihat apakah ada perbedaan pada percobaan menyalakan sebuah lampu dari browser yang berbeda. Percobaan ini menggunakan fungsi input otomatis pada kedua browser dengan settingan waktu yang sama seperti terlihat pada gambar berikut :

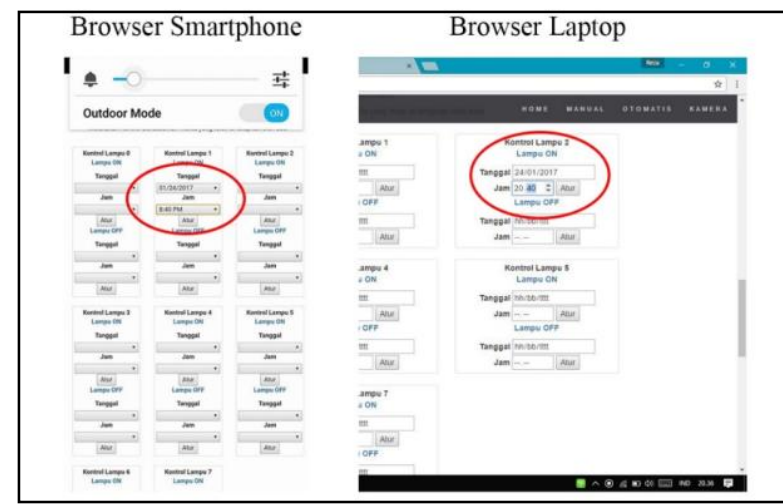

Gambar 23. Pengujian dengan Browser Smartphone dan Laptop

Berdasarkan percobaan diatas saat waktu sudah menunjukan pukul 08.40PM, lampu pada rangkaian menyala secara bersamaan. Jadi dapat disimpulkan bahwa perbedaan jenis browser tidak mempengaruhi kerja sistem.

Pengujian Suhu Raspberry Pi

Pengujian ini bertujuan untuk mengetahui suhu dari Mini PC Raspberry Pi saat digunakan atau dalam keadaan stand by menunggu perintah dan berikut adalah screencapture dari hasil pengamatan sistem dari pukul 05.00 sore sampai jam 8 pagi.

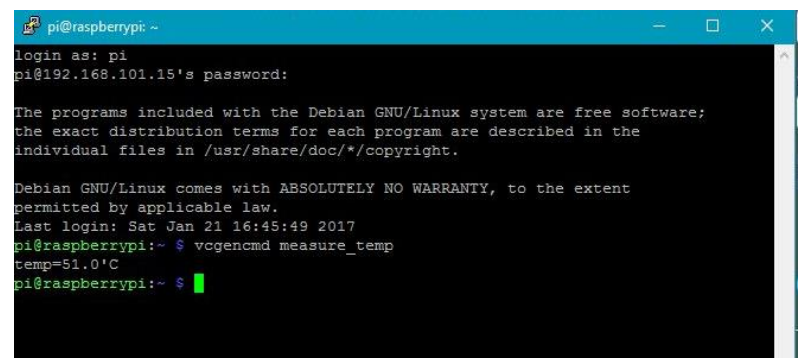

Gambar 24. Screencapture tanggl 22 januari 2017 pukul 05.00 sore

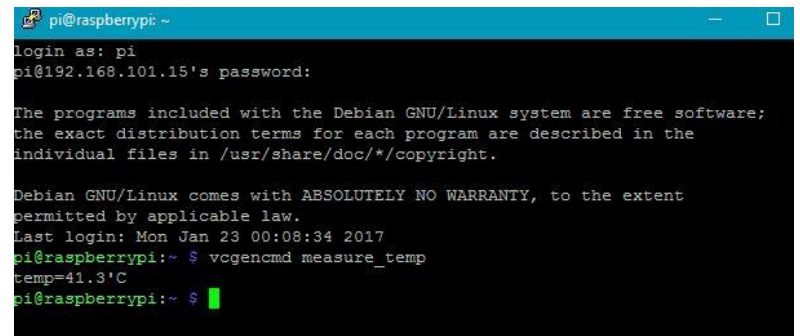

Gambar 25. Screencapture tanggl 23 januari 2017 pukul 08.00 Pagi 
Berdasarkan Gambar 19 dan 20 dapat terlihat perbedaan suhu seperti pada gambar 19 suhu menjadi naik karena pada jam tersebut banyak aktifitas yang di lakukan penguji seperti browsing dan lain lain yang berhubungan dengan kerja Raspberry $P i$, kemudian pada gambar 20 dari pukul 11.00 malam Raspberry $P i$ sudah tidak digunakan lagi atau dalam posisi stanby sampai pagi, dan setelah di cek suhu pada pagi hari turun menjadi $41^{\circ} \mathrm{C}$ jadi dapat diambil kesimpulan bahwa Raspberry $P i$ dapat dijalankan selama berhari hari karena walaupun sudah digunakan untuk proses tertentu dan saat tidak digunakan suhu dari Raspberry P $i$ dapat menurun dengan sendirinya.

\section{PENUTUP}

\section{A. Kesimpulan}

Berdasarkan hasil dari penelitian maka di ambil kesimpulan bahwa sistem pengendalian perangkat listrik menggunakan Mini PC Raspberry Pi dan Peralatan Kendali Perangkat Listrik (Relay Module) dapat mengendalikan perangkat listrik melalui Interface Website PC dengan menggunakan Kendali Manual menggunakan Tombol dan Juga dapat menggunakan penjadwalan untuk menghidupkan atau mematikan perangkat listrik menggunakan koneksi jaringan Local atau menggunakan jaringan internet, selain itu kecepatan respon sistem untuk menghidupkan dan menyalakan perangkat listrik tergantug dari kecepatan internet semakin cepat koneksi internet maka respon sistem akan semakin cepat untuk menghidupkan lampu dan begitupun sebaliknya jika koneksi lambat maka respon server akan menjadi lambat.

\section{B. Saran}

Pada pembuatan skripsi ini tentunya masih memiliki kekurangan - kekurangan yang ditemukan. Untuk itu diharapkan kedepan dapat dilakukan pengembangan dan perbaikan sistem seperti menambah Berbagai sensor pada sistem, dapat menggunakan Server sendiri untuk akses Website, dan dapat mengukur penggunaan energi listrik, agar tujuan dari efisiensi penggunaan energi listrik bisa terealisasi dengan semestinya.

\section{DAFTAR REFERENSI}

[1] Dawood, R., Qiana, F.A., \& Muchallil, S. 2014. "Kelayakan Raspberry Pi sebagai Web Server: Perbandingan Kinerja Nginx, Apache, dan Lighttpd pada PlatForm Raspberry Pi”. Jurnal Rekayasa Elektrika Vol. 11, No. 1.

[2] Kho, D. 2015. "Pengerian Relay dan Fungsinya" [Online]. Available :

http://teknikelektronika.com/pengertian-Relayfungsi-Relay.

[3] Kunarso, L. 2015. "Rancang Bangun Sistem Kontrol Listrik Berbasis Web Menggunakan Server Online Mini PC Raspberry Pi”. Skripsi Program S1 Fakultas Teknologi Informasi Universitas STIKUBANK, Semarang.
[4] Jim. 2013. "Crontab Quick Reference". [Online]. Available : http://www.adminschoice.com/crontabquick-reference.

[5] Kurniawan, D. 2015. "Membangun Aplikasi Elektronika dengan Raspberry $\mathrm{Pi} 2$ dan WhatsApp". Elex Media Komputindo, Jakarta.

[6] Muhammad D.F. 2015 "Pengembangan Application Menegement System pada website jurusan ilmu komputer". Skripsi Program S1 Universitas Lampung, Lampung.

[7] Pustaka Pedia. 2016. "Pengertian dan Rumus Energi Listrik" [Online]. Available : http://www.pustakapedia.net/2016/02/pengertiandan-rumus-energi-listrik-serta-contoh-soal-energilistrik.

[8] Supriyono, H., Widjaya, A.J., \& Supardi, A. 2013. "Penerapan Jaringan Virtual Private Network Untuk Keamanan Komunikasi Data Bagi PT. Mega Tirta Alami". WARTA, Vol .16, No.2.

[9] Wijiyanto, P.H. 2006. "Sistem Komputer". Diktat Kuliah. Sekolah Tinggi Ilmu Komputer Yos Sudarso, Purwekerto.

[10] Yudianto, M.J.N. 2007. "Jaringan Komputer Dan Pengertiannya”. Jurnal Ilmu Komputer, Semarang.

[11] https://pinout.xyz/

[12] https://www.raspberrypi.org/products/cameramodule-v2/

[13] https://docs.dataplicity.com/docs/how-it-works

\section{SEKILAS TENTANG PENULIS}

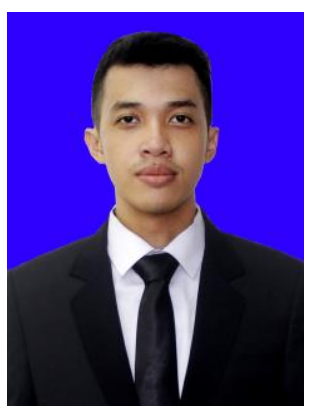

Saya bernama Mohamad Reza Nurkamiden dan merupakan anak tunggal dari pasangan Yusuf Hanafi dan Sumarni Nurkamiden, lahir di Manado pada tanggal 30 januari 1994. Asal daerah gorontalo.

Saya mulai menempuh pendidikan di sekolah dasar SDN 2 Kaliyoso (1999 -2006). Kemudian melanjutkan studi tingkat pertama di SMPN 2 Bongomeme (2006 - 2009) dan selanjutnya saya menempuh pendidikan tingkat atas di SMAN 3 Gorontalo (2006- 2009).

Setelah itu, di tahun 2012 saya melanjutkan pendidikan ke salah satu perguruan tinggi yang berada di Manado yaitu Universitas Sam Ratulangi Manado, dengan mengambil Program Studi S-1 Teknik Informatika di Jurusan Elektro Fakultas Teknik. 